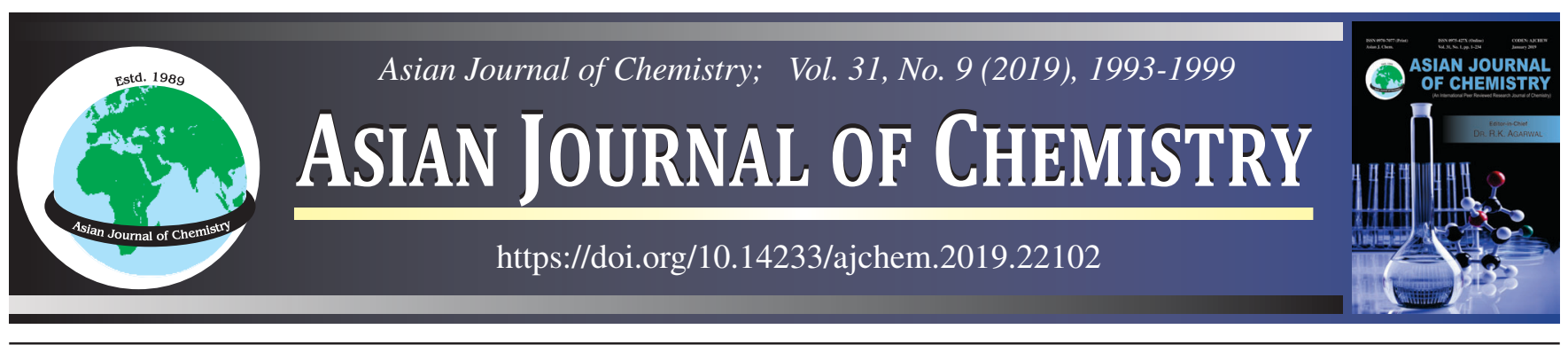

\title{
Catalytic Synthesis of Levulinate Esters over Zirconia and its Modified Forms Coated on Honeycomb Monoliths: Green Synthesis
}

\author{
Reena Saritha Serrao ${ }^{1,2,3}$, S.Z. Mohamed Shamshuddin ${ }^{1,2, *}$ and Joyce D'souZa ${ }^{3}$
}

${ }^{1}$ Research and Development Center, Bharathiar University, Coimbatore-641046, India

${ }^{2}$ Chemistry Research Laboratory, H.M.S. Institute of Technology, NH-4, Kyathsandra, Tumakuru-572104, India

${ }^{3}$ Catalysis Research Laboratory, St. Joseph's College, Bengaluru-560027, India

*Corresponding author: E-mail: em_es@rediffmail.com

Received: 28 March 2019;

Accepted: 20 April 2019;

Published online: 31 July 2019;

AJC-19488

A series of solid acid catalysts such as $\mathrm{ZrO}_{2}, \mathrm{Mo}(\mathrm{VI}) / \mathrm{ZrO}_{2}$ and $\mathrm{W}(\mathrm{VI}) / \mathrm{ZrO}_{2}$ have been coated on honeycomb monoliths as well as
synthesized in the powder forms and used as catalytic materials for synthesis of ethyl levulinate from levulinic acid and ethanol. These
solid acids were characterized by $\mathrm{BET}, \mathrm{NH}_{3}-\mathrm{TPD} / n$-butyl amine back titration, FTIR, PXRD and SEM techniques. Effects of various
reaction parameters towards the reaction performance were studied. The performance of the catalyst was tested based on nature of the
catalyst (honeycomb coated or powder form), reaction time $(1$ to $5 \mathrm{~h})$, molar ratio $(1: 1$ to $1: 12$ levulinic acid to ethanol) and reusability of
the catalytic material. An excellent yield $(86-88 \%)$ of ethyl levulinate was obtained under optimized conditions. An attempt is made to
correlate the activity of the catalysts in this esterification reaction with their surface characteristics. The honeycomb monoliths coated with
zirconia and its modified forms were found to be ecofriendly, cost-effective and reusable catalytic materials compared to their powder forms.

Keywords: Esterification, Honeycomb monolith, Levulinic acid, Levulinate esters, Modified zirconia.

\section{INTRODUCTION}

Being the heterogeneous catalysts, solid acids are beneficial in many large-volume applications, especially in the petroleum refineries, pharmaceuticals besides in the synthesis of fine chemicals $[1,2]$. Having the exceptional acidic properties, metal oxides and their modified forms can be used as catalysts and catalyst supports. Especially among metal oxides, zirconia $\left(\mathrm{ZrO}_{2}\right)$ is utilized in many industrially important organic transformations due to its flexibility and versatility. Much work [3,4] have been done on sulphated zirconia as a solid acid in the field of fine chemical synthesis. However, as sulphated zirconia undergoes rapid deactivation at high temperature, several attempts have been made to synthesize sulphate free zirconia based solid acids. Sulphate free -zirconia based solid acids such as $\mathrm{MoO}_{\mathrm{x}} / \mathrm{ZrO}_{2}$ and $\mathrm{WO}_{\mathrm{x}} / \mathrm{ZrO}_{2}$ have been synthesized and used as solid acid catalysts in a few liquid phase reactions [5-7]. It is reported that modification of $\mathrm{ZrO}_{2}$ with $\mathrm{Mo}(\mathrm{VI})$ and $\mathrm{W}(\mathrm{VI})$ ions can generate strong acid sites including super acid sites [8].
By using a proper catalyst carrier, the physico-chemical, structural and catalytic properties of metal oxides can be modified. Cordierite $\left(\mathrm{Mg}_{2} \mathrm{Al}_{4} \mathrm{Si}_{5} \mathrm{O}_{18}\right)$ honeycomb monoliths play a prominent role as catalyst carriers in heterogeneous catalysis [9]. Catalyst coated honeycomb monoliths are widely used in automotive applications which involve gas phase reactions such as combustion of volatile organic compounds (VOCs), ozone abatement in aircrafts and selective reduction of $\mathrm{NO}_{\mathrm{X}}$ [10]. The formation of thin layer of catalyst with high active surface area, less amount of catalyst loaded on the monolith, easy separation and complete recovery of the catalyst from the reaction mixture is highly possible in the catalyst coated honeycomb monoliths than powder form catalysts.

From energy to manufacturing, levulinic acid can be used in the preparation of resins, pharmaceutical agents and biofuels $[11,12]$. Levulinate ester or alkyl levulinate is synthesized from esterification reaction of levulinic acid with various alkyl alcohols [13] (Scheme-I). These levulinate esters have extensive application either in flavouring and fragrance industries or as additives in gasoline and biodiesel $[14,15]$.

This is an open access journal, and articles are distributed under the terms of the Attribution 4.0 International (CC BY 4.0) License. This license lets others distribute, remix, tweak, and build upon your work, even commercially, as long as they credit the author for the original creation. You must give appropriate credit, provide a link to the license, and indicate if changes were made. 


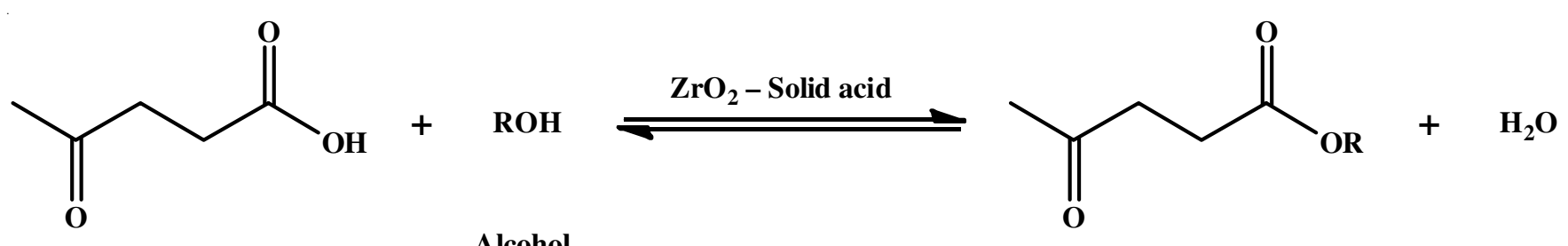

Levulinic acid

Alcohol

Alkyl levulinate

Scheme-I: Esterification of levulinic acid with an alcohol over a solid acid catalyst

Based on the advantages of honeycomb monoliths as a catalyst carrier, and industrial application of ethyl levulinate, the work done on the synthesis of cordierite honeycomb coated with solid acids such as $\mathrm{ZrO}_{2}, \mathrm{Mo}(\mathrm{VI}) / \mathrm{ZrO}_{2}$ and $\mathrm{W}(\mathrm{VI}) / \mathrm{ZrO}_{2}$, its physico-chemical characterization and catalytic activity study in liquid phase ethyl levulinate synthesis via esterification of levulinic acid is reported. The reaction parameters including nature of the catalyst, amount of catalyst, levulinic acid to ethanol ratio and reaction time in levulinic acid esterification is studied to obtain highest productivity of ethyl levulinate.

\section{EXPERIMENTAL}

Cordierite honeycomb monoliths (height $=1.20 \mathrm{~cm}$, diameter $=2.50 \mathrm{~cm}$ and hole size $=0.2 \mathrm{~cm}$ ) were used for the present work were supplied by Shreya Ceramics, Baroda, India. Zirconyl nitrate, ammonium molybdate and tungstic acid were supplied by M/s. LOBA Chemie India Ltd., India. Levulinic acid, isoamyl alcohol, $n$-butanol, $n$-pentanol and cyclohexanol were supplied by Sigma-Aldrich Chemicals Pvt. Ltd. and Fischer Scientific Pvt. Ltd., India.

Preparation of catalytic material in honeycomb coated form: Solid acids such as $\mathrm{ZrO}_{2}, 5 \% \mathrm{Mo}(\mathrm{VI}) / \mathrm{ZrO}_{2}(\mathrm{MZ})$ and $5 \%$ $\mathrm{W}(\mathrm{VI}) / \mathrm{ZrO}_{2}$ (WZ) were coated on different honeycomb monoliths by using 'dip and dry' method [16]. Before coating the active catalysts, the honeycomb monolith was wash coated with zirconia in order to increase the surface area and to have a support material which has a better interaction with the active catalyst [17]. Typically, for coating $\mathrm{ZrO}_{2}$ on bare monolith, a dilute solution containing known amount of zirconyl nitrate was prepared. The resulting solution was coated on a monolith by dipping and drying in a furnace preheated at $400{ }^{\circ} \mathrm{C}$. The dipping and drying steps were repeated for 8-10 times until $\sim 0.2 \mathrm{~g}$ of the catalyst is coated on the monolith. Similarly, bare monoliths were coated with $5 \% \mathrm{Mo}(\mathrm{VI}) / \mathrm{ZrO}_{2}$ and $5 \% \mathrm{~W}(\mathrm{VI}) /$ $\mathrm{ZrO}_{2}$ by using dilute solutions containing $0.96 \mathrm{~g}$ of zirconyl nitrate and $0.25 \mathrm{~g}$ of ammonium molybdate and $0.03 \mathrm{~g}$ tungstic acid.

The honeycomb coated with $\mathrm{ZrO}_{2}, 5 \% \mathrm{Mo}(\mathrm{VI}) / \mathrm{ZrO}_{2}$ and $5 \% \mathrm{~W}(\mathrm{VI}) / \mathrm{ZrO}_{2}$ were calcined at $550{ }^{\circ} \mathrm{C}$ for $5 \mathrm{~h}$ in a muffle furnace before its use as catalysts.

Preparation of catalytic material in powder form: $\mathrm{ZrO}_{2}$, $5 \% \mathrm{Mo}(\mathrm{VI}) / \mathrm{ZrO}_{2}$ and $5 \% \mathrm{~W}(\mathrm{VI}) / \mathrm{ZrO}_{2}$ were also prepared in powder forms by impregnation method using salts such as zirconyl nitrate, ammonium molybdate and tungstic acid. Known amounts of the required salts were taken in a china dish and made a paste with small amount of water. The paste was then dried in an air oven at $120^{\circ} \mathrm{C}$ for $12 \mathrm{~h}$ and calcined at $550{ }^{\circ} \mathrm{C}$ for $5 \mathrm{~h}$ in a muffle furnace.
Characterization of catalyst: The catalytic materials were characterized for their physico-chemical properties such as specific surface area, crystallinity, surface acidity and morphology by BET, powder XRD, $\mathrm{NH}_{3}-\mathrm{TPD} / n$-butyl amine back titration and SEM techniques, respectively. The BET surface area of the catalytic material was determined using nitrogen as the absorbent in a NOVA-1000 high-speed gas sorption analyzer. The total surface acidity was measured by $\mathrm{NH}_{3}-\mathrm{TPD}$ method as well as $n$-butyl amine back titration method using bromothymol blue indicator. The crystalline nature of catalytic materials was determined by recording their powder XRD patterns on a BRUKER eco-D8-ADVANCE system working with $\mathrm{CuK} \alpha$ radiation ( $1.5418 \AA$ ). The morphologies of catalysts were characterized by scanning electron microscopy (SEM, SU3500, HITACHI).

Catalytic activity: Catalytic activity studies were investigated in the esterification of levulinic acid with ethanol under reflux conditions. In a typical procedure, a mixture of levulinic acid and ethanol (1:8 molar ratio, total volume $=30 \mathrm{~mL})$ was taken along with known amount of catalyst (either honeycomb coated or powder forms of $\mathrm{ZrO}_{2}, 5 \% \mathrm{Mo}(\mathrm{VI}) / \mathrm{ZrO}_{2}$ and $5 \%$ $\left.\mathrm{W}(\mathrm{VI}) / \mathrm{ZrO}_{2}\right)$ in the reactor and refluxed for a definite period of time. The reaction mixture was cooled to room temperature after a specified time and analyzed for the products using GC [Netel Gas chromatograph with $2 \mathrm{~m}$ stainless steel column packed with $10 \%$ AT- $1200+1 \% \mathrm{H}_{3} \mathrm{PO}_{4}$ on W-HP]. The percentage yield of the products was calculated from the GC results based on the relative response of the different compounds in the reaction mixture with respect to levulinic acid. The catalytic activity measurements were made by varying the reaction conditions such as molar ratio of reactants, amount of catalyst, nature of catalyst and time of reflux to get higher yields and better selectivity of the product. Similarly, esterification reactions of levulinic acid with $n$-butanol, $n$-pentanol, isoamyl alcohol and cyclohexanol were carried out under a definite set of reaction conditions.

\section{RESULTS AND DISCUSSION}

The values of BET surface areas for different catalytic materials (powder form) used in this investigation are presented in Table-1. Among different catalytic materials, pure $\mathrm{ZrO}_{2}$ was found to be having least surface area, but when pure $\mathrm{ZrO}_{2}$ was incorporated with $\mathrm{Mo}(\mathrm{VI})$ or $\mathrm{W}(\mathrm{VI})$ ions the surface area increased to almost two fold. This can be explained based on the formation of Mo-O-Zr and W-O-Zr linkages in $5 \% \mathrm{Mo}(\mathrm{VI}) /$ $\mathrm{ZrO}_{2}$ and $5 \% \mathrm{~W}(\mathrm{VI}) / \mathrm{ZrO}_{2}$, respectively [18].

Powder XRD patterns of catalytic materials are presented in Fig. 1. From the powder XRD patterns of pure $\mathrm{ZrO}_{2}$, it is 
TABLE-1

PHYSICO-CHEMICAL PROPERTIES OF SOLID ACIDS USED

\begin{tabular}{cccccc}
\hline \multirow{2}{*}{ Catalyst } & $\begin{array}{c}\text { BET surface area } \\
\left(\mathrm{m}^{2} / \mathrm{g}\right)\end{array}$ & Weak & Medium & Strong & TSA \\
\cline { 3 - 6 } & 49 & 0.07 & 0.31 & - & $0.38(0.35)$ \\
$\mathrm{ZrO}_{2}$ & 121 & - & 0.25 & 0.86 & $1.11(1.13)$ \\
$\mathrm{MZ}$ & 115 & - & 0.21 & 0.83 & $1.04(1.02)$ \\
$\mathrm{WZ}$ & &
\end{tabular}

Note: Numbers in the parenthesis in column- 6 correspond to the values obtained $n$-butylamine back titration method.

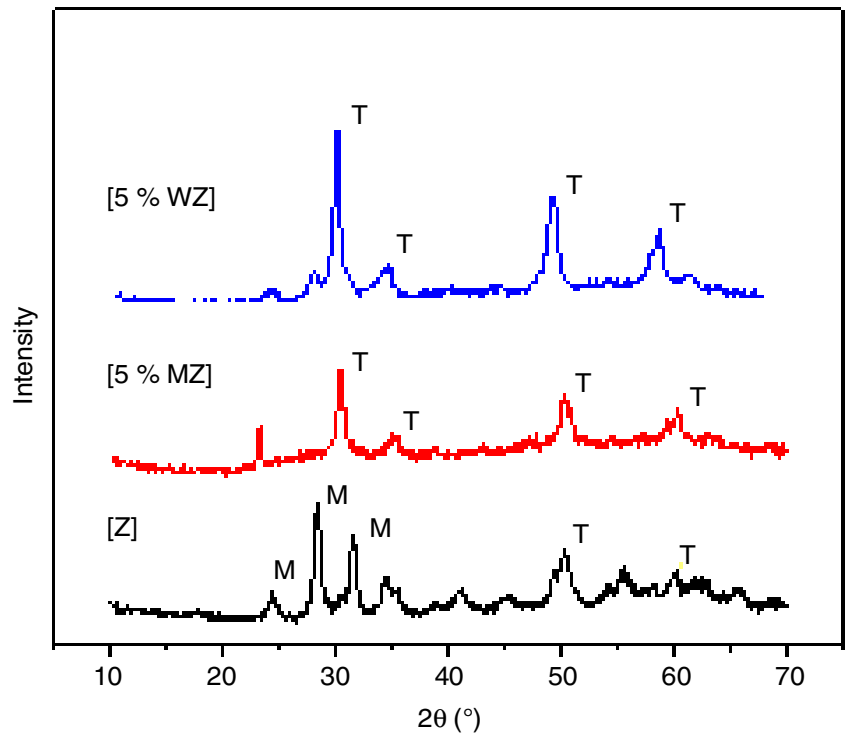

Fig. 1. Powder XRD patterns of Z, $5 \% \mathrm{MZ}$ and $5 \% \mathrm{WZ}$ [M: monoclinic; T: tetragonal]

observed that it has both monoclinic $\left(2 \theta=24.7^{\circ}, 28.4^{\circ}, 31.6^{\circ}\right)$ and tetragonal phases $\left(2 \theta=30.3^{\circ}, 35.3^{\circ}, 50.7^{\circ}\right)$. However, when it is incorporated with $\mathrm{Mo}(\mathrm{VI})$ or $\mathrm{W}(\mathrm{VI})$ ions the powder XRD patterns will change in such a way that the modified forms consists of more of tetragonal phase than monoclinic. This can be explained on the basis of strong interaction of $\mathrm{Mo}(\mathrm{VI})$ and $\mathrm{W}(\mathrm{VI})$ ions with zirconia support inhibiting the growth of monoclinic phase of zirconia [19].

The total surface acidity as well as acid site distribution of the solid acids was obtained from $\mathrm{NH}_{3}$-TPD method. Pure zirconia was found to be least acidic when compared to its modified forms i.e. $5 \% \mathrm{Mo}(\mathrm{VI}) / \mathrm{ZrO}_{2}$ and $5 \% \mathrm{~W}(\mathrm{VI}) / \mathrm{ZrO}_{2}$. Incorporation of $\mathrm{Mo}(\mathrm{VI})$ or $\mathrm{W}(\mathrm{VI})$ ions in zirconia lattice significantly increases acidic properties of zirconia due to the formation of electron deficient states into zirconia lattice, thereby generating new acid sites. Total surface acidity of the catalytic materials measured by $\mathrm{NH}_{3}$-TPD and $n$-butyl amine back titration method was found to follow the order: $\mathrm{ZrO}_{2}<5 \% \mathrm{~W}(\mathrm{VI}) /$ $\mathrm{ZrO}_{2}<5 \% \mathrm{Mo}(\mathrm{VI}) / \mathrm{ZrO}_{2}$. Between $5 \% \mathrm{Mo}(\mathrm{VI}) / \mathrm{ZrO}_{2}$ and $5 \%$ $\mathrm{W}(\mathrm{VI}) / \mathrm{ZrO}{ }_{2}, 5 \% \mathrm{Mo}(\mathrm{VI}) / \mathrm{ZrO}_{2}$ was found to be slightly more acidic than $5 \% \mathrm{~W}(\mathrm{VI}) / \mathrm{ZrO}_{2}$ catalytic material. Further, $5 \%$ $\mathrm{Mo}(\mathrm{VI}) / \mathrm{ZrO}_{2} / 5 \% \mathrm{Mo}(\mathrm{VI}) / \mathrm{ZrO}_{2}$ consists of 'moderate and strong' acid sites, whereas pure zirconia consists of 'weak and moderate' acid sites. In the literature a similar type of acid site distribution has been reported [20].

FTIR spectra of solid acids used for the present study are shown in Fig. 2. It is observed that all the samples show two common bands, which are situated at around 3500 and 1620 $\mathrm{cm}^{-1}$. The broad peak observed at $3500 \mathrm{~cm}^{-1}$ is the result of

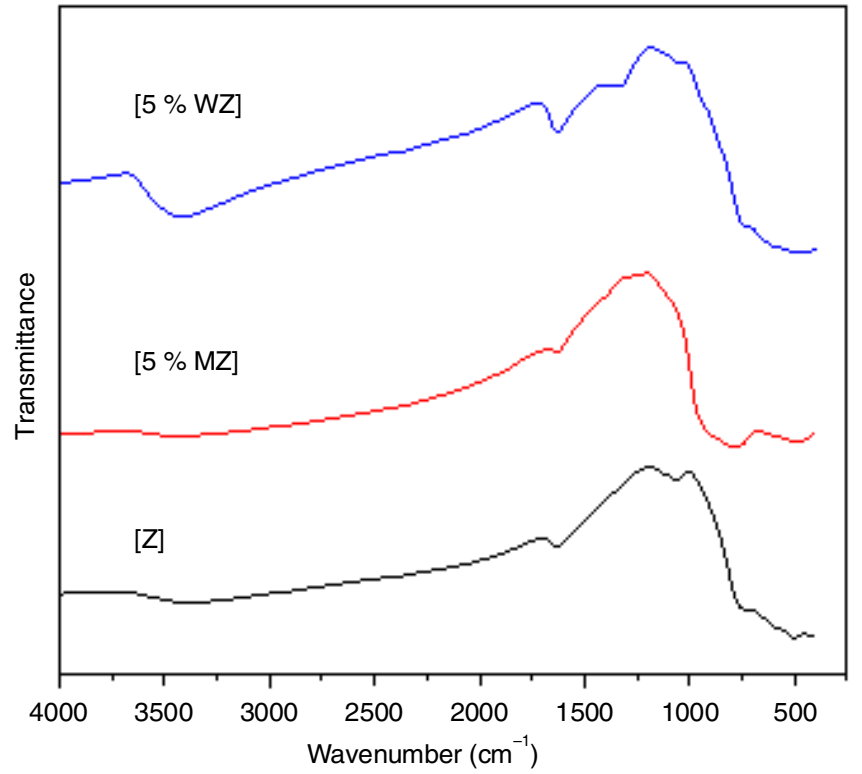

Fig. 2. FT-IR spectrum of Z, $5 \% \mathrm{MZ}$ and $5 \% \mathrm{WZ}$

surface hydroxyl groups. The band at $1620 \mathrm{~cm}^{-1}$ is due to the vibrations of acidic-OH groups [21]. In addition to these two bands, $5 \% \mathrm{Mo}(\mathrm{VI}) / \mathrm{ZrO}_{2}$ sample shows another band at $\sim 780$ $\mathrm{cm}^{-1}$ which is due to Mo-O-Mo stretching mode of vibration for $\mathrm{MoO}_{3}$ [22]. Similarly, for $5 \% \mathrm{~W}(\mathrm{VI}) / \mathrm{ZrO}_{2}$ sample, a band at $\sim 1003 \mathrm{~cm}^{-1}$ is observed which could be attributed to the symmetrical $\mathrm{W}=\mathrm{O}$ stretching mode of tungsten oxide bonded to $\mathrm{ZrO}_{2}$ surface.

SEM images of honeycomb monoliths coated with $\mathrm{ZrO}_{2}$, $5 \% \mathrm{Mo}(\mathrm{VI}) / \mathrm{ZrO}_{2}$ and $5 \% \mathrm{~W}(\mathrm{VI}) / \mathrm{ZrO}_{2}$ are shown Fig 3 . The SEM images illustrate strong and uniform coating of the active catalyst on honeycomb monoliths. The information obtained from SEM explains that the method used is convenient to get the adherent and homogeneous coating of the catalytic material on honeycomb monolith surface.

Effect of reaction parameters on esterification of levulinic acid with ethanol: The catalytic activity of different catalysts such as $\mathrm{ZrO}_{2}, 5 \% \mathrm{Mo}(\mathrm{VI}) / \mathrm{ZrO}_{2}$ and $5 \% \mathrm{~W}(\mathrm{VI}) / \mathrm{ZrO}_{2}$ (both honeycomb coated and powder forms) in the esterification of levulinic acid to ethyl levulinate under refluxing conditions was inspected by varying time of reflux, amount of catalyst, nature of the catalyst and levulinic acid to ethanol molar ratio.

Effect of nature of solid acid catalyst: A comparative study was made in levulinic acid esterification with ethanol using catalytic materials such as $\mathrm{ZrO}_{2}, 5 \% \mathrm{Mo}(\mathrm{VI}) / \mathrm{ZrO}_{2}$ and $5 \% \mathrm{~W}(\mathrm{VI}) / \mathrm{ZrO}_{2}$ in their monolithic form as well as powder forms. A 2 fold increase in the yield of ethyl levulinate was observed over monolithic form of the catalyst, inspite of using same amount of catalyst $(0.2 \mathrm{~g})$ in both forms (Fig 4a). This 

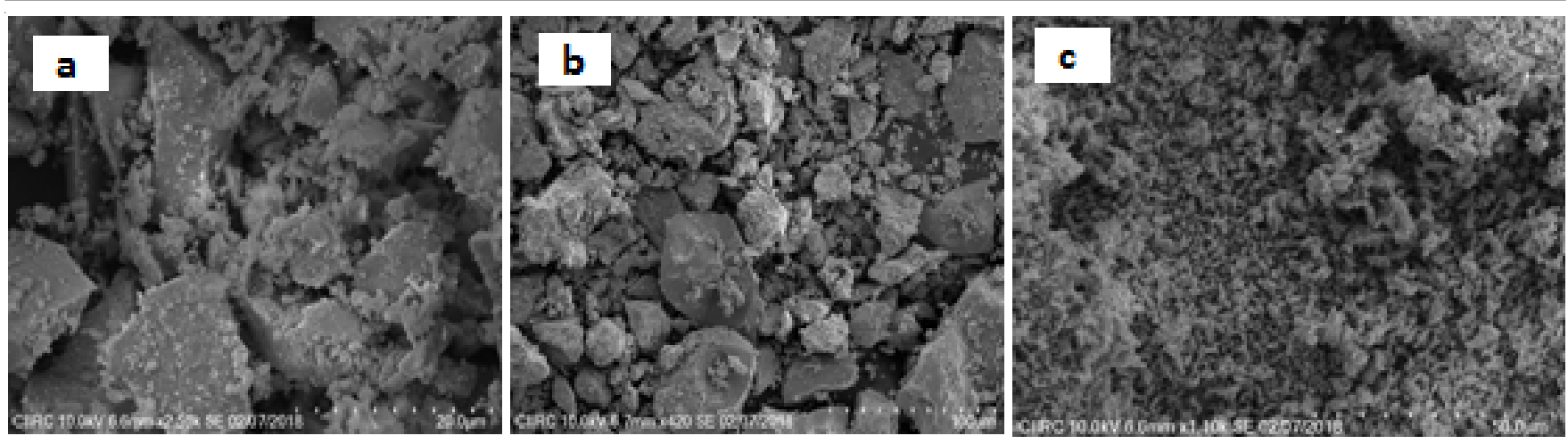

Fig. 3. SEM images of (a) honeycomb wash coated with zirconia (Z) (b) honeycomb coated with $5 \%$ MZ (c) honeycomb coated with $5 \%$ WZ
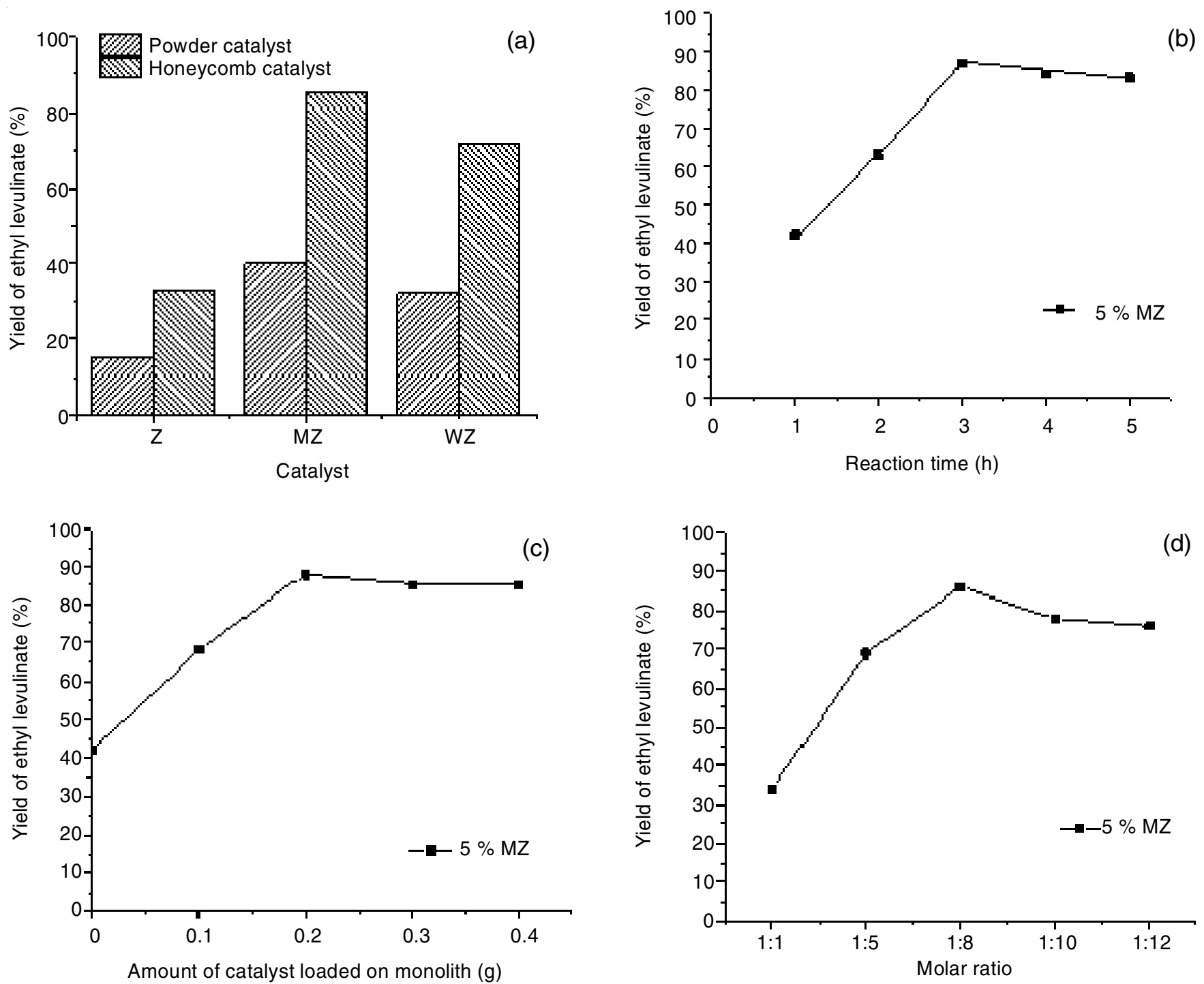

Fig. 4. (a) Effect of nature of catalysts on the yield of ethyl levulinate (molar ratio $=1: 8$; time of reflux $=3 \mathrm{~h}$, amount of catalyst $=\sim 0.2 \mathrm{~g}$ ); (b) Effect of reaction time on the yield of ethyl levulinate (molar ratio of the reactants $=1: 8$; amount of the catalyst $=\sim 0.2 \mathrm{~g}$ of $\mathrm{MZ}$ coated on the monolith); (c) Effect of amount of catalyst (MZ) coated over the monolith on the yield of ethyl levulinate (molar ratio $=1: 8$, time of reflux $=3 \mathrm{~h}$ ); (d) Effect of molar ratio on the yield of ethyl levulinate (time of reflux $=3 \mathrm{~h}$, amount of catalyst $=\sim 0.2 \mathrm{~g}$ of $\mathrm{MZ}$ coated on the monolith)

may be due to the presence of more numbers of active sites on the surface of monolithic catalyst, as in the powder form homogeneous dispersion of solid acids is not possible. The observation between the catalytic activities of two forms i.e., honeycomb coated and powder form can be explained as follows. The number of channels, their diameter and wall thickness determine the cell density (expressed as cells per square inch), which in turn allows the calculation of the geometric surface area; the sum 
of the areas of all the channel walls upon which the catalyst is deposited. This leads to one of the most important advantages of honeycomb monolith as it has a large open frontal area. The lower catalyst loading in case of monolithic catalyst is compensated by the higher efficiency due to the good masstransfer characteristic [9].

Further reactions were carried out by taking $\mathrm{ZrO}_{2}, 5 \%$ $\mathrm{Mo}(\mathrm{VI}) / \mathrm{ZrO}_{2}$ and $5 \% \mathrm{~W}(\mathrm{VI}) / \mathrm{ZrO}_{2}$ in honeycomb monolith forms at reflux temperature for $3 \mathrm{~h}$. It is observed that in all solid acids there is a good compatibility between the surface acidity and catalytic activity. Due to least acidic nature of zirconia, the yield of ethyl levulinate was found to be only 33 $\%$. But over $5 \% \mathrm{Mo}(\mathrm{VI}) / \mathrm{ZrO}_{2}$ solid acid the yield was increased up to $86-88 \%$. However, when the reactions were carried out with $5 \% \mathrm{~W}(\mathrm{VI}) / \mathrm{ZrO}_{2}$ the yield was intermediate. Hence, $5 \%$ $\mathrm{Mo}(\mathrm{VI}) / \mathrm{ZrO}_{2}$ catalyst is optimized for further studies.

Effect of reaction time: Fig. $4 \mathrm{~b}$ explains the effect of reaction time from 1 to $5 \mathrm{~h}$ over $5 \% \mathrm{Mo}(\mathrm{VI}) / \mathrm{ZrO}_{2}$ monolithic catalyst on levulinic acid esterification with ethanol at reflux temperature and 1: 8 levulinic acid to ethanol molar ratio. Yield of ethyl levulinate gradually increases with reaction time, and a maximum yield of product was obtained at $3 \mathrm{~h}$. However, with further increase of reaction time, the yield of ethyl levulinate stabilizes. Reaction time beyond $3 \mathrm{~h}$ seems to be too long and would result in formation of byproducts and in lower yield of ethyl levulinate. The formation of byproducts was confirmed by $\mathrm{GC}$ analysis. Thus reaction time of $3 \mathrm{~h}$ was selected as the optimum reaction time and retained for all further experiments.

Effect of amount of catalyst: The effect of amount of catalyst has been studied for the synthesis of ethyl levulinate by esterification over $5 \% \mathrm{Mo}(\mathrm{VI}) / \mathrm{ZrO}_{2}$ monolithic catalyst. Different amount of $5 \% \mathrm{Mo}(\mathrm{VI}) / \mathrm{ZrO}_{2}(0.1$ to $0.4 \mathrm{~g}$ ) coated on different monoliths was used to study the effect of amount of catalyst on the yield of ethyl levulinate (Fig 4c). As it is clearly visible in Fig. 4d, due to the strong catalytic activity of $5 \% \mathrm{Mo}(\mathrm{VI}) / \mathrm{ZrO}_{2}$ solid acid catalyst towards the synthesis of ethyl levulinate, a maximum yield of $86 \%$ was possible over the monolith loaded with $0.2 \mathrm{~g}$ of $5 \% \mathrm{Mo}(\mathrm{VI}) / \mathrm{ZrO}_{2}$. Never- theless even after increasing the amount of loading $5 \%$ $\mathrm{Mo}(\mathrm{VI}) / \mathrm{ZrO}_{2}$ catalyst on the monolith beyond $0.2 \mathrm{~g}$, the yield of ethyl levulinate was still stable. This is possible due to the arrangement of multilayer of the catalytic material masking the inner layer. Thus one can conclude that in this work the threshold loading of catalytic material on a honeycomb monolith is up to $0.2 \mathrm{~g}$. This helps to have better dispersion and best active catalytic surface over the monolith. Hence, for further studies $0.2 \mathrm{~g}$ was taken as the optimum weight of $5 \% \mathrm{Mo}(\mathrm{VI}) /$ $\mathrm{ZrO}_{2}$ solid acid catalyst.

Effect of molar ratio: High levulinic acid conversion is possible by minimizing the backward reaction as levulinic acid esterification with alcohol is a reversible reaction. Complete removal of water or surplus amount of alcohol in the reaction could increase the levulinic acid conversion [23]. However in the present research, as it is not feasible to eliminate water in the reaction system, excess ethanol is used in order to accelerate the reaction to forward direction. The effect of levulinic acid to ethanol molar ratio from 1:1 to 1:12 on levulinic acid esterification is illustrated in Fig 4d. Levulinic acid conversion rose from 34 to $86 \%$ when molar ratio increased from 1:1 to 1:8. This proves that the excess ethanol is conducive for the forward reaction of levulinic acid esterification. However, when molar ratio increased beyond 1:8 up to 1:12 a minute decline in levulinic acid conversion was noticed. The decrease in levulinic acid conversion is due to higher amount of ethanol might dilute the reaction mixture and inhibit the ethyl levulinate production [24,25].

From the analysis of effect of reaction parameters, the optimum conditions to maximize the levulinic acid esterification with ethanol are $0.2 \mathrm{~g}$ of $5 \% \mathrm{Mo}(\mathrm{VI}) / \mathrm{ZrO}_{2}$ coated on the honeycomb, $3 \mathrm{~h}$ reaction time and 1:8 of levulinic acid to ethanol molar ratio.

Effect of nature of alcohol: The levulinic acid esterification was carried out with $n$-butanol, $n$-pentanol, isoamyl alcohol and cyclohexanol under optimized conditions i.e., $0.2 \mathrm{~g}$ of $5 \% \mathrm{Mo}(\mathrm{VI}) / \mathrm{ZrO}_{2}$ coated on the honeycomb catalyst at reflux temperature for $3 \mathrm{~h}$ with molar ratio of levulinic acid: alcohol $(\mathrm{R})=1: 8$. The results are presented in Fig. 5a.
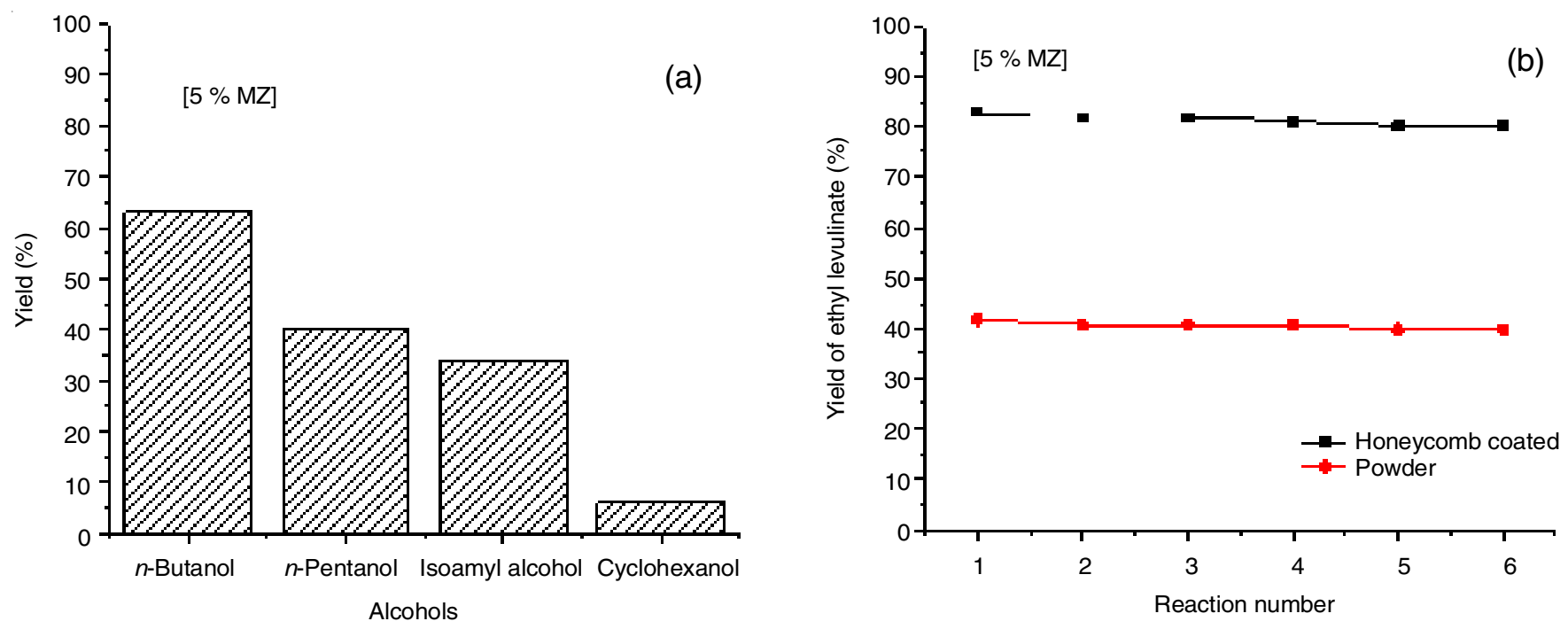

Fig. 5. (a) Effect of nature of the alcohol on the yield of ethyl levulinate (molar ratio $=1: 8$, time of reflux $=3 \mathrm{~h}$, amount of catalyst $=\sim 0.2 \mathrm{~g}$ of $\mathrm{MZ}$ coated on the monolith). (b) Effect of reusability of the catalyst in powder and honeycomb coated forms on the yield of ethyl levulinate (molar ratio $=1: 8$, time of reflux $=3 \mathrm{~h}$, amount of catalyst $=\sim 0.2 \mathrm{~g}$ of MZ) 
It is evident that higher levulinic acid conversions were achieved from levulinic acid esterification with shorter chain alcohol. From the analyses, $63 \%$ conversion was obtained from levulinic acid esterification with $n$-butanol compared to 40 and $34 \%$ for levulinic acid esterification with $n$-pentanol and isoamyl alcohol, respectively. Longer chain alcohol might enhance the steric effect and hinders the alkyl levulinate production. Among different alcohols, cyclohexanol being secondary alcohol it showed very less yield due to more steric hindrance compared to primary alcohols.

Effect of reactivation: Since reusability is an essential factor in heterogeneous catalysis, the stability of monolithic catalyst was scrutinized by examining the performance of regenerated catalyst. The honeycomb catalysts recovered from the reaction mixture were washed with acetone, dried at $120^{\circ} \mathrm{C}$ for $2 \mathrm{~h}$, calcined at $550{ }^{\circ} \mathrm{C}$ for $2 \mathrm{~h}$ and reused for synthesis of ethyl levulinate under the optimum conditions. The results are shown in Fig. 5b. As it is also observed that even after six reaction cycles, the catalytic activity of recycled catalyst did not decrease significantly, showing its good stability for esterification of levulinic acid. Also while comparing the catalytic activity of $0.2 \mathrm{~g}$ of $5 \% \mathrm{Mo}(\mathrm{VI}) / \mathrm{ZrO}_{2}$ (both powder and honeycomb coated catalyst), we can observe that, even though same amount of catalyst was used in powder as well as monolithic form, a $~ 2$ fold increase in the yield of ethyl levulinate was found over honeycomb coated form of the catalyst.
Proposed mechanism of levulinic acid esterification with ethanol: Mechanism of catalytic esterification of levulinic acid with ethanol catalyzed by solid acid catalyst can be elucidated in Scheme-II. Initially, the adsorption of levulinic acid on the catalyst Brønsted acid sites resulted in the formation of protonated levulinic acid intermediate thus increases the electrophilicity of carbonyl carbon. An oxonium ion is formed by the attack of nucleophilic oxygen of ethanol on carbonyl carbon atom. A proton transfer from the oxonium ion yielded a new oxonium ion. In the next step, ethyl levulinate is formed through the loss of water followed by the deprotonation step. As a result, the regeneration of catalyst acid sites occurred from the deprotonation step $[15,26]$.

\section{Conclusion}

From the above studies, it may be concluded that ethyl levulinate can be conveniently synthesized by liquid phase esterification of levulinic acid with ethanol using $\mathrm{ZrO}_{2}, 5 \%$ $\mathrm{Mo}(\mathrm{VI}) / \mathrm{ZrO}_{2}$ and $5 \% \mathrm{~W}(\mathrm{VI}) / \mathrm{ZrO}_{2}$ catalysts. Among all the solid acid catalysts, $\mathrm{Mo}(\mathrm{VI}) / \mathrm{ZrO}_{2}$ exhibited good conversion of levulinic acid (86-88 \%) with $100 \%$ selectivity towards ethyl levulinate. This catalyst can be extended to synthesize other levulinate esters, effectively. Having the catalytically active tetragonal phase of zirconia as well as moderate and strong acid sites, it is evident that $\mathrm{Mo}(\mathrm{VI}) / \mathrm{ZrO}_{2}$ is an efficient and convenient solid acid catalytic material for the production of

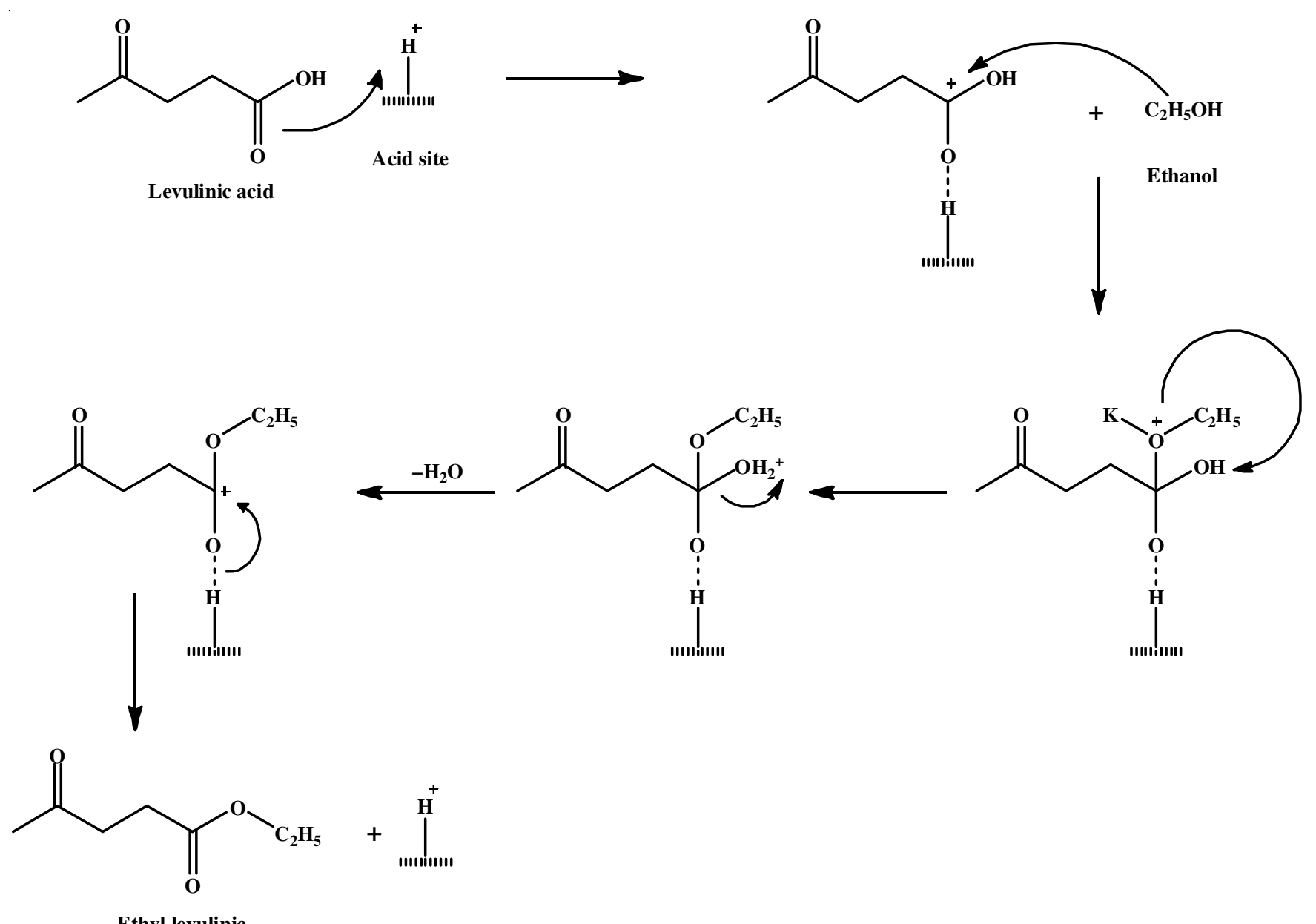

Ethyl levulinic

Scheme-II: Mechanism of esterification of levulinic acid with ethanol over protonic acid sites 
ethyl levulinate. A linear correlation between the total surface acidity, powder XRD phases and catalytic activity of catalysts was also observed. In order to be cost effective and eco friendly the use of honeycomb monoliths as catalyst carriers for $\mathrm{ZrO}_{2}$ and its modified forms is recommended.

\section{ACKNOWLEDGEMENTS}

The authors thank Vision Group on Science and Technology (VGST), Government of Karnataka (GoK) (GRD-375) for providing the financial assistance.

\section{CONFLICT OF INTEREST}

The authors declare that there is no conflict of interests regarding the publication of this article.

\section{REFERENCES}

1. J. Otera, Chem. Rev., 93, 1449 (1993); https://doi.org/10.1021/cr00020a004.

2. A. Corma, S. Iborra, S. Miquel and J. Primo, J. Catal., 173, 315 (1998); https://doi.org/10.1006/jcat.1997.1930.

3. B.M. Reddy and M.K. Patil, Chem. Rev., 109, 2185 (2009); https://doi.org/10.1021/cr900008m.

4. S.Z. Mohamed Shamshuddin, Synlett, 361 (2005); https://doi.org/10.1055/s-2004-837228.

5. X. Song and A. Sayari, Catal. Rev., Sci. Eng., 38, 329 (1996); https://doi.org/10.1080/01614949608006462.

6. G.D. Yadav and J.J. Nair, Micropor. Mesopor. Mater., 33, 1 (1999); https://doi.org/10.1016/S1387-1811(99)00147-X.

7. M. Hino and K. Arata, Chem. Commun., 851 (1980); https://doi.org/10.1039/C39800000851.

8. M. Hino and K. Arata, Chem. Commun., 1259 (1988); https://doi.org/10.1039/c39880001259.

9. T.A. Nijhuis, M.T. Kreutzer, A.C.J. Romijn, F. Kapteijn and J.A. Moulijn, Chem. Eng. Sci., 56, 823 (2001); https://doi.org/10.1016/S0009-2509(00)00294-3.

10. R.M. Heck, S. Gulati and R.J. Farrauto, Chem. Eng. J., 82, 149 (2001); https://doi.org/10.1016/S1385-8947(00)00365-X.

11. F.G. Cirujano, A. Corma and F.X. Llabrés i Xamena, Chem. Eng. Sci., 124, 52 (2015); https://doi.org/10.1016/j.ces.2014.09.047.
12. Y. Wang, F. Vogelgsang and Y. Roman-Leshkov, ChemCatChem, 7, 916 (2015); https://doi.org/10.1002/cctc.201403014.

13. N.A.S. Ramli and N.A.S. Amin, Bioenerg. Res., 10, 50 (2017); https://doi.org/10.1007/s12155-016-9778-3.

14. A. Demolis, N. Essayem and F. Rataboul, ACS Sustain. Chem. Eng., 2, 1338 (2014); https://doi.org/10.1021/sc500082n.

15. D. Song, S. An, B. Lu, Y. Guo and J. Leng, Appl. Catal. B, 179, 445 (2015); https://doi.org/10.1016/i.apcatb.2015.05.047.

16. M. Shyamsundar, S.Z.M. Shamshuddin and C.U. Aniz, J. Am. Oil Chem. Soc., 92, 335 (2015); https://doi.org/10.1007/s11746-015-2609-4.

17. K.C. Patil, M.S. Hegde, R. Tanu and H.T. Aruna, Chemistry of Nano Crystalline Oxide Materials, Combustion Synthesis, Properties and Applications, World Scientific Publishng Pvt. Ltd.: Singapore (2008).

18. B.M. Reddy, B. Chowdhury and P.G. Smirniotis, Appl. Catal. A: Gen., 211, 19 (2001); https://doi.org/10.1016/S0926-860X(00)00834-6.

19. B.M. Reddy and V.R. Reddy, Synth. Commun., 29, 2789 (1999); https://doi.org/10.1080/00397919908086446.

20. B.M. Reddy and M.K. Patil, Chem. Rev., 109, 2185 (2009); https://doi.org/10.1021/cr900008m.

21. J.R. Sohn, E.W. Chun and Y.I. Pae, Bull. Korean Chem. Soc., 24, 1785 (2003); https://doi.org/10.5012/bkcs.2003.24.12.1785.

22. K.V.R. Chary, K.R. Reddy, G. Kishan, J.W. Niemantsverdriet and G. Mestl, J. Catal., 226, 283 (2004); https://doi.org/10.1016/j.jcat.2004.04.028.

23. K.Y. Nandiwale, S.K. Sonar, P.S. Niphadkar, P.N. Joshi, S.S. Deshpande, V.S. Patil and V.V. Bokade, Appl. Catal. A, 460-461, 90 (2013); https://doi.org/10.1016/j.apcata.2013.04.024.

24. K.Y. Nandiwale and V.V. Bokade, Chem. Eng. Technol., 38, 246 (2015); https://doi.org/10.1002/ceat.201400326.

25. C.R. Patil, P.S. Niphadkar, V.V. Bokade and P.N. Joshi, Catal. Commun., 43, 188 (2014); https://doi.org/10.1016/j.catcom.2013.10.006.

26. G. Pasquale, P. Vazquez, G. Romanelli and G. Baronetti, Catal. Commun., 18, 115 (2012); https://doi.org/10.1016/j.catcom.2011.12.004. 